\title{
Attitude towards tele rehabilitation-based therapy services and its associated factors among health professional working in specialized teaching hospitals in Amhara region, Northwest Ethiopia,2021
}

Habile Sidelil ( $\square$ habsi1981@gmail.com )

Arba Minch

Adina Demissie

Institute of Public Health, University of Gondar

Getu Debalke

Institute of Public Health, University of Gondar

Binyam Tilahun

Institute of Public Health, University of Gondar

Berhanu Fikade

Institute of Public Health, University of Gondar

Samuel Hailegebreal

Arba Minch University

Research Article

Keywords: Tele-rehabilitation, health professional, attitude, digital literacy

Posted Date: October 1st, 2021

DOI: https://doi.org/10.21203/rs.3.rs-929351/v1

License: (9) (1) This work is licensed under a Creative Commons Attribution 4.0 International License. Read Full License 


\section{Abstract \\ Background}

Tele-rehabilitation is part of Tele-health $(\mathrm{TH})$ which provides a rehabilitation service at a distance through telecommunication technology. Lack of enough trained professionals, lack of access, transportation cost, long waiting time, and difficulty of mobility to reach rehabilitation services are problems faced during face-to-face rehabilitation services. The significance of this study is to assess the attitudes and associated factors of health professionals about TR services.

\section{Method}

An institutional-based cross-sectional quantitative study design was conducted among 408 participants from March to April 2021. Study units were selected by using a simple random sampling technique. Epi-data 3.1 versions were used to enter data, while SPSS version 20 was used to conduct analysis. A bivariable and multivariable logistic regression was used to determine factors associated with the attitude of health professionals towards tele-rehabilitation.

\section{Result}

A total of 408 participants responded to the 423 survey questionnaires distributed. A response rate of $96.45 \%$ was achieved for this study. Out of the 408 respondent's majority, 285(69.9\%) of health professionals had good attitude towards tele rehabilitation-based treatment services. Among the factors good knowledge of tele rehabilitation AOR $1.76(95 \% \mathrm{Cl}: 1.078,2.879)$, digitally literate AOR $1.74(95 \% \mathrm{Cl}: 1.028,2.954)$, perception on security and privacy AOR $0.56(95 \% \mathrm{Cl}: 0.333,0.944)$, and owns smart mobile phone AOR 1.9 (95\%Cl: 1.007 , 3.781) were significantly associated with attitude of tele rehabilitation.

\section{Conclusion}

The majority of the respondents had a good attitude towards tele rehabilitation services. Having own mobile, knowledge towards tele rehabilitation, digital literacy, perception on security and privacy to rehabilitation was found to be the most important determinant factor for the attitude of health professionals towards tele rehabilitation. As a result, the government and other responsible entities should consider enacting systems and strategies to encourage the use of mobile technologies for the management of disability and chronic diseases.

\section{Background}

Today, information communication technologies (ICTs) such as computer, mobile phones and others are accessible to most people(1). Information technology in healthcare is commonly used as an important tool in improving healthcare quality, accessibility, distribution and reducing discrimination based on shortage of access to information and as a technique of responding quickly to issues that threaten one's personal or community's well-being (2). Tele-rehabilitation is a part of tele-health, which uses telecommunication 
technology to deliver rehabilitation services at a distance. Assessment, monitoring, prevention, intervention, management, education, consulting, counseling, and treatment through the education of impaired patients and family members are examples of such services(3). It is provided to people who live in remote areas or who are unable to travel to a rehabilitation center due to a disability, financial restrictions, or being elderly, as well as those who do not have access to a hospital. Tele rehabilitation requires technologies such as smartphones and computers(4). It can also use video communication technologies and social media accounts such as Facebook messenger video chat, Google Hangouts video, Skype, and email(5). Thus, with these applications, the patient will only need a mobile phone, a tablet, a computer, and an internet connection to communicate with the health care provider(5). Approximately fifteen percent of the world's population, or more than one billion people, live with some form of disability due to different complication(6). Around 80 million people are disabled in Africa(7). whereas, in Ethiopia it accounts for nine percent of the total population(8). Around 84\% are assumed to live in rural areas and have limited access to basic services(9). The scarcity of medical specialists, the inadequate transportation infrastructure and due to the difficulty of mobility in reaching rehabilitation center makes it even more difficult to provide healthcare in remote and rural areas(10).a study conducted in Saudi Arabia(11), Pakistan(12) and Nigeria(3) shows using tele rehabilitation for patients who have disability is the best service method. This study will help the specialized teaching hospital better understanding how to use information technology to help people with disability.

This finding will serve as a basis for policymakers, researchers, and anyone interested in TR or disability patient care to build effective methods. Therefore, this study assesses the attitudes and associated factors of health professionals about TR services.

\section{Method}

\section{Study design and setting}

An institutional-based cross-sectional quantitative study design was conducted in the Amhara region, north west Ethiopia. The Amhara region is located in the North-Western part of Ethiopia. It has 10 administrative zones, one special zone, 181 woredas, and 78 urban centers. The capital city of the State of Amhara is BahirDar. It has around 85 hospitals ( 2 specialized teaching referral hospitals, 6 referral hospitals, more than 4 general hospitals, and around 73 primary hospitals), more than 850 health centers, and around 3,350 health posts. Currently, there were more than five rehabilitation center offices in teaching, referrals, and general hospitals of the region. These studies were conducted at specialized teaching hospitals namely the University of Gondar and Tibebe Ghion Specialized teaching referral hospitals. Each hospital is estimated to serve five million people in their catchment area. More than two thousand health professionals are working in these two hospitals.

\section{Study population and data collection}

All health professionals who were currently working at Amhara region specialized teaching referral hospitals were the study population, the sample size was determined based on the assumption of single population proportion formula. A stratified sampling procedure was used by considering professions as strata. Finally, participants were chosen from each profession using a simple random sampling technique. In this Study attitude was measured by a five-point Likert scale of attitude question which categorized into good and poor 
depending on the threshold which was computed using the demarcation threshold formula. Self-administered

pretested structured questionnaires adapted and modified from different kinds of literature. Data was collected by four trained data facilitators guided by two supervisors. To control the quality of data training was given for the data facilitator for one day.

\section{Statistical data analysis}

The data was cleaned to check for errors and missed values and corrected accordingly. The data entry form was prepared with Epi-data 3.1 versions and analyses were conducted using SPSS version 20. The binary logistic regression method was used to identify independent variables associated with dependent Variables having a $p$-value of $<0.2$ and multivariate analysis were conducted to show the relationship between multiple independent variables and dependent variables. P-value lees than or equal to 0.05 was taken as a cut of value to be significant. Adjusted odds ratio (AOR) with a 95\% confidence interval (Cl) was used to make interpretations of the result.

Ethics approval and consent to participate

Ethical clearance was obtained from the ethical review board institute of public health at the University of Gondar. Written consent was taken from university of Gondar and Tibebe Ghion teaching specialized hospital.

\section{Results}

\section{Socio-demographic characteristics of health professionals in Amhara Region Teaching hospital, 2021}

A total of 408 health professionals completed the survey questionnaires with a response rate of $96.5 \%$. The majority (73.3\%) of the non-respondents were from the University of Gondar teaching hospital. In this study, the majority of the participants were males, 259(63.5\%). The mean age was 27.85+_3.951 SD years and the majority of respondents were less than 30 years of age. Regarding to educational level, the majority (81.1\%) of the participants were bachelor's degrees and below. Majority $69.9 \%$ of the participants have working experience of less than or equal to four years (Table 1)

Access to basic technology among health professional in Amhara Region Teaching Specialized Hospital, 2021

The majority of 288 (70.6\%) of health professionals have a personal computer. However, less than $50 \%$ of health professionals indicated their personal computers had internet capabilities. Regarding smartphones, more than $86 \%$ of health professionals have their own smartphones. Furthermore, from the participants, only $35(8.6 \%)$ of health professionals indicated that they did not have a social media account. (Table 2)

\section{Knowledge of Health professionals towards Tele-rehabilitation}

The majority 261(64\%) of health professionals had good knowledge of Tele-rehabilitation-based therapy services. Among the respondents, 243(64.3\%) were heard about Tele rehabilitation-based therapy services (figure 1).

Organizational related variable on attitudes of HP towards Tele rehabilitation 
Of the total respondents, $160(39.2 \%)$ of the study participants were took computer-related training. More than half $217(53.2 \%)$ of the health professionals had internet access in the office or clinical practice (Table 3 )

\section{Technological related variable of health professional}

Among the total of the respondents, $241(59.1 \%)$ have high digital literacy. More than half $210(51.5 \%)$ of health professionals had negative perceptions of the security and privacy of Tele rehabilitation technology (figure 2).

\section{Attitude of health professionals towards Tele-rehabilitation}

From the total of 408 respondent's majority, 285(69.9\%) of health professionals had good attitude towards Tele rehabilitation-based treatment services (figure 3 )

Factors associated with the attitude of health professionals towards Tele-rehabilitation-based therapy services.

In a Bivariate analysis educational level, profession, experience, own computer, own smartphone, computerrelated training, IT support staff in the organization, internet access in an organization, knowledge towards telerehabilitation, digital literacy, perception on security and privacy, were found significantly associated with attitudes towards tele rehabilitation at a p-value $<0.2$. In multivariate analysis knowledge towards telerehabilitation, digital literacy, perception of security and privacy on tele rehabilitation, and own smart phone were significantly associated with attitudes towards tele rehabilitation at P-value<0.05 (table 4).

With respect to knowledge respondents who have good knowledge towards tele rehabilitation-based therapy services were 1.7 (AOR: 1.761 $(1.078,2.879)$ times higher to have a good attitude on tele rehabilitation-based therapy services than those who have poor knowledge about TR services.

Participants who have high digital literacy were 1.7 (AOR: 1.743(1.028, 2.954), times more likely to have good attitudes towards tele-rehabilitation-based therapy services than those who did not have digital literacy. Health professionals who had a negative perception of security and privacy about tele rehabilitation-based treatment services were $44 \%$ (AOR: $0.561(95 \% \mathrm{Cl}: 0.333,0.944)$, less likely to have good attitudes towards tele rehabilitation than those who have a positive perception of privacy and security towards tele rehabilitation services. Respondents who have their smartphones were 1.9(AOR: 1.951(95\% Cl: 1.007, 3.781) times higher to have a good attitude towards tele rehabilitation-based therapy services than those who did not have smartphones or access to mobile phones. (Table 4)

\section{Discussion}

This study aimed to assess the attitude and associated factors of health professionals towards tele rehabilitation for a disability, chronic disease management, and for diseases that require physical distancing.

Our findings indicated that the overall attitudes of health professionals toward TR were good, with $69.9 \%$ of health professionals had to have a good attitude (Cl: 65.38-74.32). This finding is following the study conducted in Tehran majority of health care providers had a positive attitude towards Tele rehabilitation (13). 
Also similar to the study in Saudi Arabia on tele rehabilitation (11). In the same way, studies conducted in India reported that the attitude of healthcare providers was good, such as a survey conducted on the attitude towards tele-dentistry shows $70 \%$ of healthcare providers had a positive attitude (14), a similar study on postgraduate dental students shows $71.1 \%$ of respondents had positive attitudes (15), a survey on the attitude of telemedicine reported that $70 \%$ of health professional have a favorable attitude towards telemedicine (16) And a study on attitude towards a mobile-based exercise majority of care provider had a good attitude(17).

Likewise, a survey that assesses the attitude towards healthcare ICT and home follow up in Sweden, indicated that $70 \%$ of health professionals have a positive attitude (18). On the other hand, this finding is slightly lower than the study conducted in Germany on app-based therapy among health professionals (77.2\%) of participants who had a good attitude (19). Similarly, slightly higher findings were reported in the study conducted in Egypt on telemedicine where $75 \%$ of dermatologists have a good attitude towards telemedicine (20). Also, a study in Libya was higher than this study indicated (82\%) of health professionals had a good attitude to telemedicine during covid 19 pandemics(21). This discrepancy might be due to technological infrastructure, training towards e-health, low attention to e-health, and management support. But, this finding is better compared to a study conducted in Ethiopia on telemedicine which indicated, $64 \%$ of health professionals have a good attitude (22). The possible explanation is due to the study period (the study was conducted 4 years ago). Further, this could be due to taking courses towards e-health and telemedicine for clinical staff and also graduates of clinical fields and due to studies conducted about telemedicine and another e-health program.

In this finding, knowledge of tele rehabilitation was significantly associated with the attitude of tele rehabilitation (AOR: 1.761(95\% Cl: 1.078, 2.879). Health professional who had good knowledge of TR were a positive attitude towards TR services. This is in line with other studies which indicate knowledge towards tele rehabilitation could have a positive association with having a good attitude. (23). This finding is supported by the study conducted in Saudi Arabia on knowledge and attitudes towards tele rehabilitation indicates that lack of knowledge of tele rehabilitation is limiting the use of tele rehabilitation(24). These findings is similar to those of Pakistan who maintain that lack of ICT knowledge among practitioners and concerns around patient confidentiality were among the factors that limit the practice of tele rehabilitation(12). This study is consistent with the study conducted in Tehran (13) and Saudi Arabia (25).

The most important technology to address tele rehabilitation services is the mobile phone. In this study, the majority of health professionals have mobile phone access and own smartphones, which were significantly associated with health professionals' attitudes toward tele rehabilitation (AOR: 1.951). (95 percent Cl: 1.007, 3.781). Participants who own smartphones were 1.9 times more likely to have a good attitude towards telerehabilitation than those who didn't have smartphones. This finding was consistent with the study conducted in Ethiopia(26) and Germany (19).

Furthermore, respondents who had high digital literacy were 1.7 times more likely to have a good attitude towards TR compared to those who have low digital literacy (AOR: 1.743(95\%Cl: 1.028, 2.954). This finding is consistent with the study finding in Ethiopia (26)(27), Sweden(18), Saudi Arabia(23), Pakistan(12),

German (19) and Libya (21) (28). 
In this finding perception of security and privacy towards tele rehabilitation is significantly associated with attitudes towards tele rehabilitation (AOR: $0.561(955 \mathrm{Cl}: 0.333,0.944)$. More than half of health professionals (51.5\%) had a negative perception of privacy and security of information about tele rehabilitation technologybased therapy services. Health professionals who had a negative perception of security and privacy towards tele rehabilitation are $44 \%$ less likely than those who had positive perceptions of security and privacy towards Tele rehabilitation. this finding is supported by the study conducted in Saudi Arabia on Tele rehabilitation among health care providers indicated the majority of the participants considered that patient data security and patient privacy are at risk is associated with Tele-rehabilitation services (24) (25). In the other comparison, this study is similar to the study in Germany on app-based therapy. (19) Australia (29) and Pakistan (12).

\section{Conclusion}

This research has found significant proportions of healthcare providers from teaching hospitals have a favourable attitude towards Tele rehabilitation-based therapy services. Overall, this research identifies that access to basic technologies, individual, and tele rehabilitation-related factors can affect the attitude of health professionals. Having own mobile, knowledge towards Tele rehabilitation, digital literacy, perception on security and privacy to rehabilitation was found to be the most important determinant factor for the attitude of health professionals towards Tele rehabilitation. According to this finding, the majorities of participants had a smartphone and have strong feelings about Tele rehabilitation-based therapeutic services. As a result, the government and other responsible entities should consider enacting systems and strategies to encourage the use of mobile technologies in disability and chronic disease management.

\section{Abbreviations}

Adjusted odd ratio (AOR), Confidence interval (CI), Corona virus disease 2019(COVID19), Crude odd ratio (COR), Information communication technology (ICT), Information technology (IT), Odd ratio (OR), Tele rehabilitation (TR), Tele therapy (TT).

\section{Declarations}

\section{Ethics approval and consent to participate}

Ethical approval to conduct the study was obtained from the University of Gondar ethical review board. Communication with the different official administrators of each teaching hospital was made through a formal letter obtained from the University of Gondar. The purposes and data privacy issues of the study were enlightened to every individual study participant and their written informed consent was taken before the study. We confirm that all methods were carried out in accordance with the relevant guidelines and regulations.

\section{Consent for publication}

Not applicable.

\section{Availability of data and materials}


Full data set and materials pertaining to this study can be obtained from corresponding author on reasonable request

\section{Competing interests}

The authors declare that they have no competing interests.

\section{Funding}

No funding was obtained for this study

\section{Author information}

\section{Affiliations}

Arba Minch College of Health Sciences, Department of Health Informatics, Arba Minch, Ethiopia.

\section{Habile Sidelil}

College of Medicine and Health Sciences, Institute of Public Health, Department of Health Informatics, University of Gondar, Gondar, Ethiopia.

\section{Adina Demissie, Getu Debalke, Binyam Tilahun \& Berhanu Fikade}

College of Medicine and Health Sciences, Institute of Public Health, Department of Health promotion, University of Gondar, Gondar, Ethiopia.

\section{Samuel Hailegebreal}

Arba Minch University, College of Medicine and Health Sciences, School of Public Health Department of Health Informatics, Ethiopia

\section{Contributions}

Proposal preparation, acquisition of data, analysis and Interpretation of data was done by HS. Drafting the article, revising it critically for intellectual content, and final approval of the version to be published was done by HS, AD, GD, BT, BF and SA. All authors read and approved the final manuscript.

\section{Corresponding author}

Habile Sidelil

Acknowledgment

We would like to thank the University of Gondar, for its support during the study. We also thank all data collectors and survey respondents for their contributions.

\section{References}


1. Marwaa MN, Ytterberg C, Guidetti S. Significant others' perspectives on person-centred information and communication technology in stroke rehabilitation-a grounded theory study. Disability and rehabilitation. 2020;42(15):2115-22.

2. Yusif S, Hafeez-Baig A, Soar J. e-Health readiness assessment factors and measuring tools: A systematic review. International Journal of Medical Informatics. 2017;107:56-64.

3. Mbada C, Baderinwa T, Sanuade C, Fatoye C, Maikudi L, Fatoye F. Awareness, Attitude and Expectations of Physiotherapy Students on Telerehabilitation. Medical Science Educator. 2021;31(2):627-36.

4. Aloyuni S, Alharbi R, Kashoo F, Alqahtani M, Alanazi A, Alzhrani M, et al., editors. Knowledge, attitude, and barriers to telerehabilitation-based physical therapy practice in Saudi Arabia. Healthcare; 2020: Multidisciplinary Digital Publishing Institute.

5. Rabanifar N, Abdi K. Letter to Editor: Telerehabilitation: A Useful and appropriate approach for people with disability in Covid-19 pandemic. Medical Journal of the Islamic Republic of Iran. 2021;35:18.

6. Organization WH. World Bank. World report on disability. Geneva: World Health Organization; 2011. 2018.

7. Krahn GL. WHO World Report on Disability: a review. Disability and health journal. 2011;4(3):141-2.

8. Zeleke WA, Hughes T, Chitiyo M. The path to an autism spectrum disorders diagnosis in Ethiopia: Parent perspective. American Journal of Orthopsychiatry. 2018;88(3):316.

9. Kebed YM. Early-Childhood-Intervention Strategies and Services: Situation of Families of Children with Developmental Disability in Addis-Ababa, Ethiopia: Evangelical Theological College; 2017.

10. Weldegebrial TT, Berhie G. Telehealth in Ethiopia-The Barriers Vs. The Success Factors. no December. $2016 ; 2017$.

11. Ullah S, Maghazil AM, Qureshi AZ, Tantawy S, Moukais IS, Aldajani AA. Knowledge and attitudes of rehabilitation professional toward telerehabilitation in Saudi Arabia: A cross-sectional survey. Telemedicine and e-Health. 2021;27(5):587-91.

12. Zahid Z, Atique S, Saghir MH, Ali I, Shahid A, Malik RA. A commentary on telerehabilitation services in Pakistan: current trends and future possibilities. International journal of telerehabilitation. 2017;9(1):71.

13. Movahedazarhouligh S, Vameghi R, Hatamizadeh N, Bakhshi E, Moosavy Khatat SM. Feasibility of telerehabilitation implementation as a novel experience in rehabilitation academic centers and affiliated clinics in Tehran: assessment of rehabilitation professionals' attitudes. International journal of telemedicine and applications. 2015;2015.

14. Nagarajappa R, Aapaliya P, Sharda AJ, Asawa K, Tak M, Pujara P, et al. Teledentistry: Knowledge and attitudes among dentists in Udaipur, India. Oral Health Dent Manag. 2013;12(502):2.

15. Pradhan D, Verma P, Sharma L, Khaitan T. Knowledge, awareness, and attitude regarding teledentistry among postgraduate dental students of Kanpur city, India: A questionnaire study. Journal of education and health promotion. 2019;8.

16. Zayapragassarazan Z, Kumar S. Awareness, knowledge, attitude and skills of telemedicine among health professional faculty working in teaching hospitals. Journal of clinical and diagnostic research: JCDR. 2016;10(3):JC01.

17. Mahmood A, Blaizy V, Verma A, Stephen Sequeira J, Saha D, Ramachandran S, et al. Acceptability and attitude towards a mobile-based home exercise program among stroke survivors and caregivers: A cross- 
sectional study. International journal of telemedicine and applications. 2019;2019.

18. Gund A, Lindecrantz K, Schaufelberger M, Patel H, Sjöqvist BA. Attitudes among healthcare professionals towards ICT and home follow-up in chronic heart failure care. BMC medical informatics and decision making. 2012;12(1):1-12.

19. Biebl JT, Huber S, Rykala M, Kraft E, Lorenz A. Attitudes and Expectations of Health Care Professionals Toward App-Based Therapy in Patients with Osteoarthritis of the Hip or Knee: Questionnaire Study. JMIR mHealth and uHealth. 2020;8(10):e21704.

20. Elsaie ML, Shehata HA, Hanafi NS, Ibrahim SM, Ibrahim HS, Abdelmaksoud A. Egyptian dermatologists attitude toward telemedicine amidst the COVID19 pandemic: a cross-sectional study. Journal of Dermatological Treatment. 2020:1-7.

21. Elhadi M, Elhadi A, Bouhuwaish A, Alshiteewi FB, Elmabrouk A, Alsuyihili A, et al. Telemedicine Awareness, Knowledge, Attitude, and Skills of Health Care Workers in a Low-Resource Country During the COVID-19 Pandemic: Cross-sectional Study. Journal of Medical Internet Research. 2021;23(2):e20812.

22. Biruk K, Abetu E. Knowledge and attitude of health professionals toward telemedicine in resource-limited settings: a cross-sectional study in North West Ethiopia. Journal of healthcare engineering. 2018;2018.

23. Aloyuni S, Alharbi R, Kashoo F, Alqahtani M, Alanazi A, Alzhrani M, et al., editors. Knowledge, Attitude, and Barriers to Telerehabilitation-Based Physical Therapy Practice in Saudi Arabia. Healthcare; 2020 : Multidisciplinary Digital Publishing Institute.

24. Ullah S, Maghazil AM, Qureshi AZ, Tantawy S, Moukais IS, Aldajani AA. Knowledge and attitudes of rehabilitation professional toward telerehabilitation in Saudi Arabia: A cross-sectional survey. Telemedicine and e-Health. 2020.

25. Alnobani O, Zakaria N, Temsah M-H, Jamal AA, Alkamel N, Tharkar S. Knowledge, Attitude, and Perception of Health Care Personnel Working in Intensive Care Units of Mass Gatherings Toward the Application of Telemedicine Robotic Remote-Presence Technology: A Cross-Sectional Multicenter Study. Telemedicine and e-Health. 2021.

26. Seboka BT, Yilma TM, Birhanu AY. Factors influencing healthcare providers' attitude and willingness to use information technology in diabetes management. BMC medical informatics and decision making. 2021;21(1):1-10.

27. Yehualashet $G$, Asemahagn $M$, Tilahun $B$. The attitude towards and use of electronic medical record system by health professionals at a referral hospital in northern Ethiopia: Cross-sectional study. Journal of Health Informatics in Africa. 2015;3(1).

28. Rettinger L, Klupper C, Werner F, Putz P. Changing attitudes towards teletherapy in Austrian therapists during the COVID-19 pandemic. Journal of Telemedicine and Telecare. 2021:1357633X20986038.

29. Rettinger L, Klupper C, Werner F, Putz P. Changing attitudes towards teletherapy in Austrian therapists during the COVID-19 pandemic. Journal of Telemedicine and Telecare.1357633X20986038.

\section{Tables}

Table 1 Socio-demographic characteristics of health professionals in Amhara region specialized teaching hospital, North West Ethiopia, 2021 


\begin{tabular}{|c|c|c|}
\hline Variable & Frequency & $100 \%$ \\
\hline \multicolumn{3}{|l|}{ GENDER } \\
\hline Male & 259 & 63.5 \\
\hline Female & 149 & 36.5 \\
\hline \multicolumn{3}{|l|}{ AGE } \\
\hline$<30$ & 308 & 75.5 \\
\hline$>=30$ & 100 & 24.5 \\
\hline \multicolumn{3}{|l|}{ PROFESSION } \\
\hline Nurse & 195 & 47.5 \\
\hline Physician & 178 & 43.6 \\
\hline Others & 35 & 8.6 \\
\hline \multicolumn{3}{|l|}{ EDUCATIONAL LEVEL } \\
\hline Degree and below & 331 & 81.1 \\
\hline Master and above & 77 & 18.9 \\
\hline \multicolumn{3}{|l|}{ WORK EXPERIENCE } \\
\hline$<4 y r s$ & 285 & 69.9 \\
\hline$>=4 y r s$ & 123 & 30.1 \\
\hline \multicolumn{3}{|l|}{ SALARY } \\
\hline$<6000$ & 61 & 15 \\
\hline $6001-8000$ & 135 & 33.1 \\
\hline 8001-10000 & 137 & 33.6 \\
\hline$>10000$ & 71 & 8.4 \\
\hline
\end{tabular}

Table 2 Access to basic technologies among health professionals at the University of Gondar and Tibebe Ghion Specialized teaching hospitals, North West Ethiopia, 2021 


\begin{tabular}{|c|c|c|}
\hline VARIABLE & Frequency & Precent \\
\hline \multicolumn{3}{|c|}{ having personal computer } \\
\hline Yes & 288 & 70.6 \\
\hline No & 120 & 29.4 \\
\hline \multicolumn{3}{|c|}{ having internet on computer } \\
\hline Yes & 185 & 45.8 \\
\hline No & 103 & 24.8 \\
\hline \multicolumn{3}{|c|}{ having smartphone } \\
\hline Yes & 351 & 86 \\
\hline No & 57 & 14 \\
\hline \multicolumn{3}{|c|}{ having internet on a smartphone } \\
\hline Yes & 272 & 66.7 \\
\hline No & 86 & 21.1 \\
\hline \multicolumn{3}{|c|}{ having social media account } \\
\hline Yes & 373 & 91.4 \\
\hline No & 35 & 8.6 \\
\hline
\end{tabular}

Table 3 Organization related variable on the attitude of health professional in Amhara Region Specialized Teaching Hospital, North West Ethiopia, 2021

\begin{tabular}{|c|c|c|}
\hline Variable & Category & $\mathrm{N}(\%)$ \\
\hline \multirow[t]{3}{*}{$\begin{array}{l}\text { Have you taken any computer-related training that can support your patient } \\
\text { management? }\end{array}$} & yes & $160(39.2)$ \\
\hline & No & 248(60.8) \\
\hline & yes & 243(59.6) \\
\hline & No & $165(40.4)$ \\
\hline \multirow{2}{*}{ Do you think you have internet access in your office or clinical practice? } & yes & $217(53.2)$ \\
\hline & No & $191(46.8)$ \\
\hline
\end{tabular}


Table 4 Bivariable and multivariable analysis of the selected variables associated with attitudes towards Tele rehabilitation service among healthcare providers, in Amhara region Specialized Teaching Hospital, North West Ethiopia, 2021. 


\section{Attitude towards Tele rehabilitation}

Characteristics

$\operatorname{Good}(n=285) \quad \operatorname{poor}(n=123) \quad$ COR-95\%Cl

AOR- $95 \% \mathrm{Cl}$

Gender

Male

$178(68.7 \% \quad 81(31.2 \%)$

$1.159(0.744,1.806)$

$0.776(0.463,1.302)$

Female

$107(71.8 \%)$

$42(28.18 \%)$

1 1

nurse

$129(66.1 \%) \quad 66(33.8 \%)$

1

1

Profession

physician

$129(72.47 \%)$

$49(27.52 \%)$

$1.347(0.865,2.097)$

$1.387(0.736,2.614)$

others

$27(77.1 \%)$

$8(22.8 \%)$

$1.727(0.743,4.011) \quad 2.316(0.873,6.142)$

Educational level

Degree\& below

$$
233(70.3 \%) \quad 98(29.7 \%)
$$

$1.143(0.671,1.946)$

$1.496(0.759,2.949)$

Masters

\& above

$$
52(67.5 \%)
$$

$25(32.4 \%)$

1

1

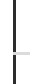

$\begin{array}{llllll}\text { Age } & <30 & 216(70.13 \%) & 92(29.87 \%) & 1.055(0.647,1.720) & 0.906(0.452,1.817) \\ & >=30 & 69(69 \%) & 31(31 \%) & 1 & 1\end{array}$

\begin{tabular}{llllll}
\hline & $<6000$ & $44(72.1 \%)$ & $17(27.9 \%)$ & 1 & 1 \\
\hline Salary & $\begin{array}{l}61000- \\
8000\end{array}$ & $93(68.8 \%)$ & $42(31.2 \%)$ & $0.856(0.439,1.668)$ & $0.639(0.306,1.336)$ \\
\hline $\begin{array}{l}81000- \\
10000\end{array}$ & $91(66.42 \%)$ & $46(33.58 \%)$ & $0.764(0.394,1.483)$ & $0.451(0.203,1.004)$ \\
\hline$>10000$ & $57(76 \%)$ & $18(24 \%)$ & $1.223(0.566,2.644)$ & $0.662(0.253,1.734)$ \\
\hline
\end{tabular}

\section{Experience}

$\begin{array}{lllll}<4 \text { years } & 192(67.36 \%) & 93(32.6 \%) & 0.666(0.412,1.077) & 0.526(0.273,1.016) \\ >4 \text { years } & 93(75.6 \%) & 30(24.9 \%) & 1 & 1\end{array}$

$\begin{array}{llll}\text { own computer } \quad \text { Yes } \quad 207(71.87 \%) & 81(28.12 \%) & 1.376(0.873,2.168)\end{array}$ 


$\begin{array}{lllll}\text { No } & 78(65 \%) & 42(35 \%) & 1 & 1\end{array}$

\begin{tabular}{|c|c|c|c|c|c|}
\hline $\begin{array}{l}\text { own } \\
\text { smartphone }\end{array}$ & Yes & $254(72.15 \%)$ & $98(27.85 \%)$ & $2.090(1.175,3.719)$ & $1.951(1.007,3.781) *$ \\
\hline & No & $31(55.35 \%)$ & $25(44.65 \%)$ & 1 & \\
\hline
\end{tabular}

$\begin{array}{clllll}\text { Knowledge } & \text { Good } & 200(70.63 \%) & 61(23.37 \%) & 2.392(1.548,3.695) & 1.761(1.078,2.879) * \\ & \text { Poor } & 85(58.95 \%) & 62(41.05 \%) & 1 & 1\end{array}$

$\begin{array}{cccccc}\text { digital literacy } & \text { Yes } & 189(78.43 \%) & 52(21.57 \%) & 2.688(1.742,4.419) & 1.743(1.028,2.954) * \\ & \text { No } & 96(57.49 \%) & 71(42.5 \%) & 1 & 1\end{array}$

\begin{tabular}{llllll}
$\begin{array}{l}\text { security and } \\
\text { privacy }\end{array}$ & Yes & $160(80.8 \%)$ & $38(19.19 \%)$ & 1 & 1 \\
& No & $125(59.53 \%)$ & $85(40.47 \%)$ & $0.349(0.223,0.547)$ & $0.561(0.333,0.944) *$ \\
& & & & & \\
& Yes & $125(78.125 \%)$ & $35(21.875 \%)$ & $1.964(1.245,3.100)$ & $1.102(0.637,1.908)$ \\
\hline $\begin{array}{l}\text { computer } \\
\text { training }\end{array}$ & No & $160(64.52 \%)$ & $88(35.48 \%)$ & 1 & \\
\hline
\end{tabular}

\begin{tabular}{lccccc}
$\begin{array}{l}\text { internet } \\
\text { support staff }\end{array}$ & Yes & $182(74.8 \%)$ & $61(25.2 \%)$ & $1.796(1.170,2.756)$ & $1.061(0.593,1.899)$ \\
\hline & No & $103(62.42 \%)$ & $62(37.5 \%)$ & 1 & \\
& & & & & \\
\hline $\begin{array}{l}\text { internet } \\
\begin{array}{l}\text { access in } \\
\text { office }\end{array}\end{array}$ & Yes & $169(77.89 \%)$ & $48(22.11 \%)$ & $2.276(1.477,3.508$ & $1.510(0.860,2.651)$ \\
& No & $116(60.74 \%)$ & $75(39.26 \%)$ & 1 & 1 \\
\hline
\end{tabular}

\section{Figures}




\section{Source of information about Telerehabilitation}

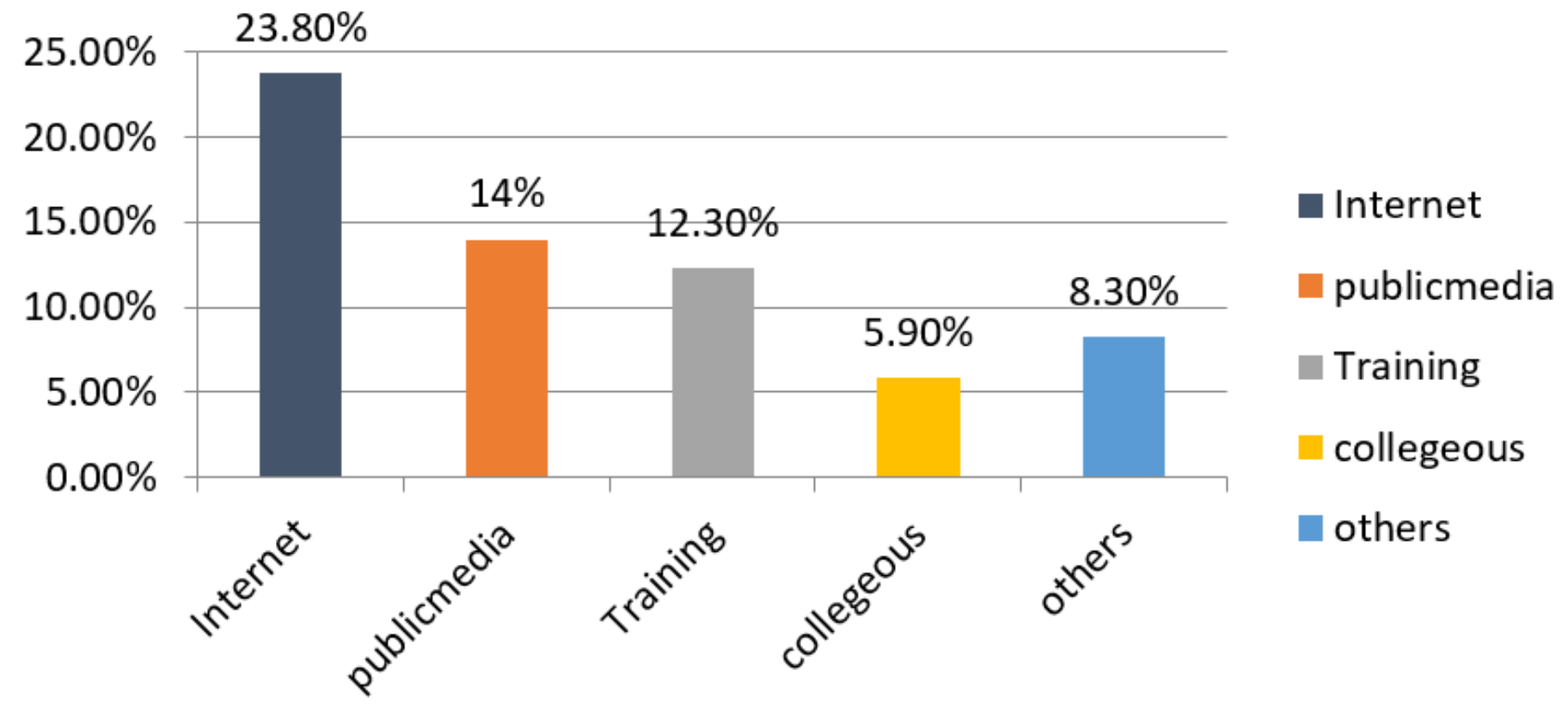

Figure 1

Source of information about Tele rehabilitation among health professionals in Amhara Region Specialized teaching Hospitals, North West Ethiopia, 2021 


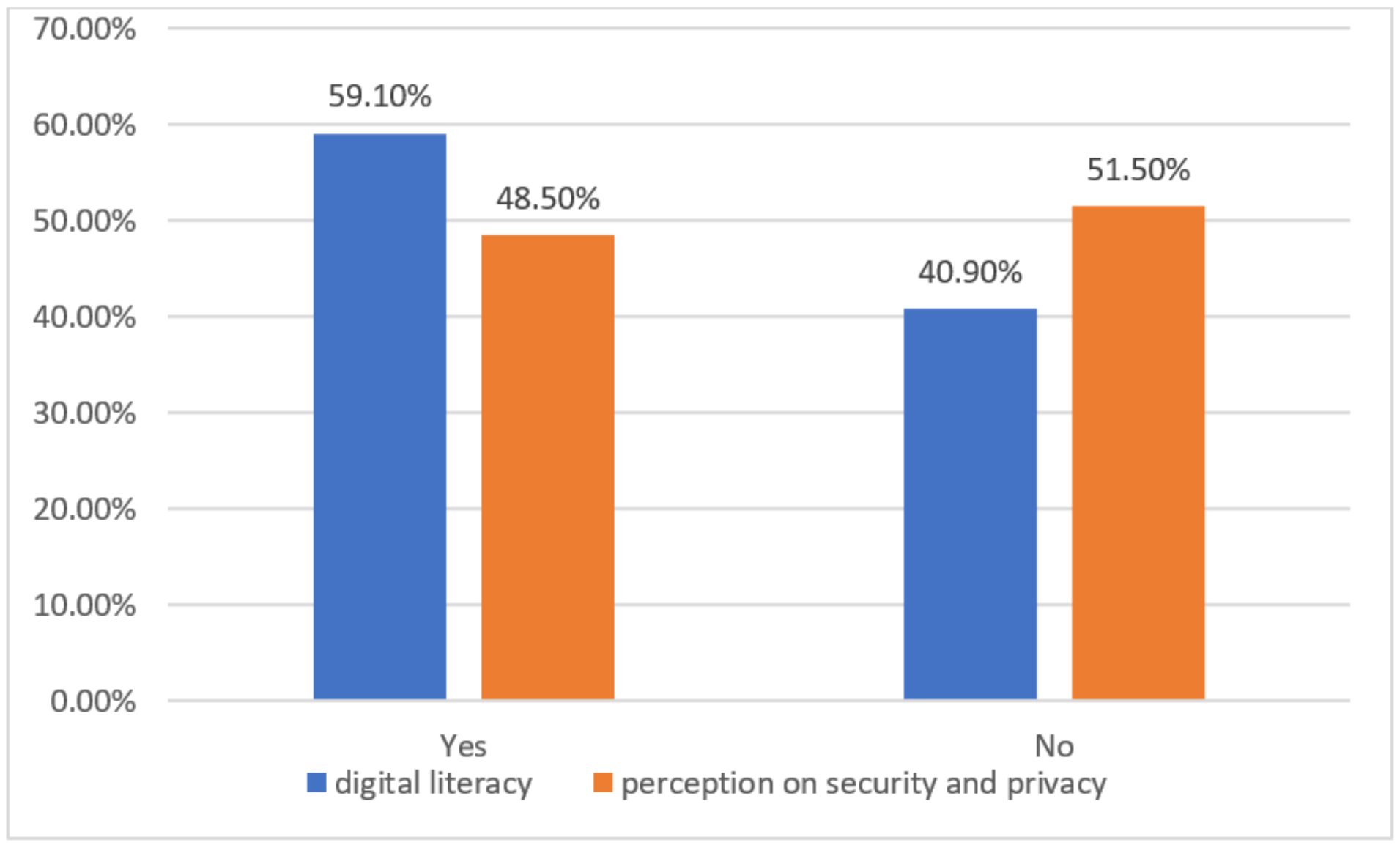

\section{Figure 2}

Technological factors towards Tele rehabilitation among health professional in Amhara region specialized teaching Hospital, 2021 


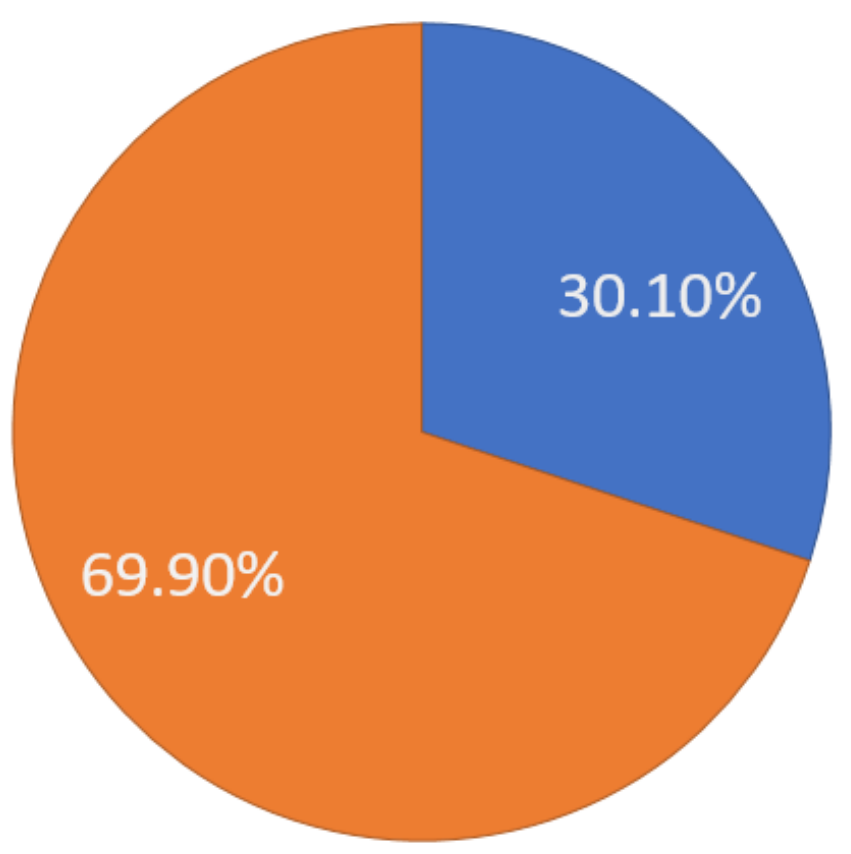

poor

good

Figure 3

Attitudes towards tele rehabilitation-based therapy services among health professional in Amhara Region specialized teaching hospital, North West Ethiopia, 2021 